Реферат. Статья знакомит с работой круглого стола «Кому и зачем нужна программа поддержки детского и юношеского чтения?», который состоялся 3 декабря 2016 г. в Российской национальной библиотеке. Его заседание прошло в рамках Международной научно-практической конференции «Чтение: многообразие возможностей» на V Санкт-Петербургском международном культурном форуме. Участники мероприятия обсудили концепцию создания Национальной программы поддержки детского и юношеского чтения в Российской Федерации. Прозвучали предложения специалистов в области культуры и образования для включения в Национальную программу поддержки детского и юношеского чтения. Высказана необходимость разработки и принятия на государственном уровне такого документа.

Ключевые слова: Национальная программа поддержки детского и юношеского чтения в Российской Федерации, продвижение чтения, поддержка чтения детей и подростков, профессиональные мероприятия, V Санкт-Петербургский международный культурный форум.

Для цитирования: Глухова Л.В., Ялышева В.В. О поддержке детского и юношеского чтения на V СанктПетербургском международном культурном форуме // Библиотековедение. 2017. Т. 66, № 1. С. 49 -54.

$\mathrm{C}$ овременной площадкой для открытого диалога и обмена опытом между специалистами в сфере культуры, представителями государственной власти, политиками и бизнесменами стал V Санкт-Петербургский международный культурный форум, состоявшийся $1-3$ декабря 2016 года. Профессиональный поток представляли 14 секций, каждая из которых охватывала определенную область культурной деятельности [1]. В рамках секции «Литература и чтение», одной из ключевых экспертных площадок Форума, состоялось шесть мероприятий.

Международная научно-практическая конференция «Чтение: многообразие возможностей», прошедшая в Российской национальной библиотеке (РНБ) 2-3 декабря, стала значимым событием Форума. Ее непосредственными организаторами выступили центр чтения РНБ и секция по чтению Российской библиотечной ассоциации (РБА). В работе приняли участие 217 человек из 32 регионов России и 6 специалистов из ближнего и дальнего зарубежья (Армении, Беларуси, Германии, Литвы, Украины и Финляндии). За месяц до открытия конференции на портале «Чтение-21» появилась ее виртуальная площадка, на которой к 1 декабря было опубликовано 64 доклада [2]. Трансляция заседаний осуществлялась в режиме онлайн (в настоящее время запись доступна для просмотра на сайте Центра чтения РНБ [3]).

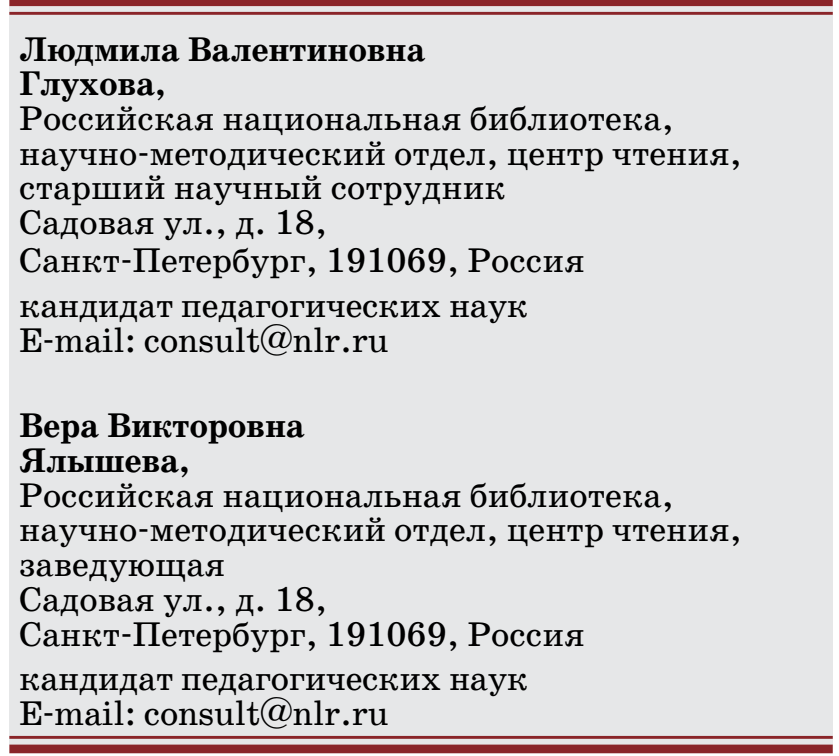

Характерной чертой конференции стал междисциплинарный подход к рассмотрению проблем чтения. $K$ участию в научной дискуссии и обсуждению практической деятельности были приглашены библиотековеды, социологи, культурологи, преподаватели вузов, школьные учителя и воспитатели детских садов, специалисты федеральных, региональных, публичных, университетских, детских и школьных библиотек, книгоиздатели и книгораспространители, писа- 
тели, представители различных общественных институций, занимающиеся проблемами читательской деятельности, продвижением книги и чтения. Организаторы предложили обсудить актуальные процессы трансформации чтения в информационном обществе. Особое внимание было уделено библиотеке как институту поддержки и продвижения чтения.

В первый день в ходе пленарного заседания в центре рассмотрения находились следующие темы: чтение в эпоху постграмотности, многообразие чтения и библиотечное обслуживание, исследовательская деятельность в области чтения, визуализация текста в культуре и образовании, технологическая и методическая поддержка чтения, особенности работы с текстами на разных носителях.

Второй день был посвящен обсуждению разработанной в 2016 г. концепции Национальной программы поддержки детского и юношеского чтения в Российской Федерации. Формат работы - круглый стол - позволил услышать и обсудить мнения представителей самых разных профессиональных групп, занимающихся проблемами детского чтения, создал условия для дискуссии, в ходе которой сталкивались различные взгляды на деятельность институтов поддержки чтения, их задачи и возможности взаимодействия. Неоднозначность существующих подходов к решению вопросов поддержки детского чтения организаторы вынесли в название круглого стола - «Кому и зачем нужна программа поддержки детского и юношеского чтения?».

В России в 2006 г. была разработана Национальная программа поддержки и развития чтения, которая так и не получила статус государственной. Однако ее значение и опыт внедрения в регионах страны нельзя недооценивать. Последние несколько лет были ознаменованы инициативами и созданием новых государственнообщественных институций, например, появился главный книжный фестиваль страны «Красная площадь», почетными гостями которого стали первые лица государства. На фестивале в 2015 г. директор Российской государственной детской библиотеки (РГДБ) М.А. Веденяпина обратилась к Президенту Российской Федерации В.В. Путину с просьбой о поддержке комплектования детских библиотек новыми книгами. На эти цели из резервного фонда Президента Российской Федерации было выделено 50 млн рублей. На фестивале в 2016 г. М.А. Веденяпина вновь привлекла внимание к проблемам детского чтения, выдвинув идею создания Национальной программы поддержки детского чтения и обосновав необходимость ее разработки. Во исполнение поручения Председателя Правительства РФ Д.А. Медведева от 11.06.2016 № ДМ-П39-3482 Министерство связи и массовых коммуникаций Российской Федерации и Федеральное агентство по печати и массовым коммуникациям (Роспечать) с участием ведущих экспертов в области образования, культуры, литературы, издательского и библиотечного дела подготовили концепцию Национальной программы поддержки детского и юношеского чтения в Российской Федерации.

Принципиальной особенностью этого документа стал его междисциплинарный и межведомственный характер. К работе над концепцией были подключены разные профессиональные коллективы, ведущие специалисты в области чтения, представители науки, образования, культуры. Документ прошел ряд согласований и экспертиз Роспечати и был передан для утверждения Правительством РФ. Как отметил на церемонии открытия V Санкт-Петербургского международного культурного форума заместитель руководителя Роспечати В.В. Григорьев, ожидается подписание концепции и принятие решения о разработке на ее основе Национальной программы поддержки детского и юношеского чтения в Российской Федерации.

Ведущими круглого стола на тему «Кому и зачем нужна программа поддержки детского и юношеского чтения? » выступили заведующий научно-методическим отделом РНБ С.А. Басов, а также главные разработчики концепции этого документа - директор РГДБ М.А. Веденяпина, президент Межрегионального центра библиотечного сотрудничества Е.И. Кузьмин, заместитель директора РГДБ по науке и издательской деятельности О.П. Мезенцева. В начале обсуждения прозвучали два установочных доклада, посвященных проблемам и перспективам приобщения детей к письменной культуре и чтению.

Выступивший с научным обоснованием концепции Е.И. Кузьмин в докладе «Приобщение детей к письменной культуре и чтению: проблемы и перспективы» подчеркнул, что 10 лет усилий по реализации Национальной программы поддержки и развития чтения не привели к существенным результатам, так как она, не став государственной, не получила соответствующего финансирования. С точки зрения государства институты, предназначенные для приобщения населения к книге и чтению, не в полной мере справляются с поставленной задачей. Информационная среда сегодня принципиально меняется, растут ее объем и сложность, неуклонно снижается доля текстовой информации, возрастает значение визуальной коммуникации, появляются прогнозы о том, что через 10-15 лет следующее поколение россиян будет не в состоянии решать глобальные проблемы развития общества. Преодолению негативных и формированию позитивных тенденций и должна способствовать Национальная программа поддержки детского и юношеского чтения в Российской Федерации. Прежде всего, она должна быть обращена к институтам поддержки чтения, воздействовать на эффективность приобщения 
детей к письменной культуре. Особое внимание в докладе было уделено анализу понятий «приобщение к чтению» и «приобщение к письменной культуре». Во имя будущего общество должно прилагать усилия к тому, чтобы подрастающее поколение не просто умело читать, а в полном объеме могло понимать значения текстов, грамотно писать и логично излагать свои мысли.

Характеризуя концепцию Программы, М.А. Веденяпина в своем выступлении подчеркнула роль и значение межведомственного подхода. В документе отражена необходимость целенаправленной работы с родителями, зафиксирована роль семьи в приобщении ребенка к чтению. Важно задействовать всю систему образования: детские сады, среднюю и высшую школу, школьные библиотеки. Концепция учитывает значение учреждений культуры и искусства, особое место отведено публичным и детским библиотекам, которые должны меняться в соответствии с современными запросами. Необходимо обновлять не только методы и приемы привлечения детей к чтению, но и библиотечные помещения, качество и состав фондов, кадровые ресурсы. Без изменений самой библиотечной среды позитивных результатов достичь не удастся. Прошедший в 2016 г. Всероссийский конкурс «Самый читающий регион», показал, что наибольший вклад в дело поддержки чтения вносят именно библиотеки, реализуя актуальные проекты. При этом содержание, масштабы и эффективность проектной работы библиотек во многом зависят от адекватного финансирования.

Вопросы подготовки кадров рассматривались как один из ключевых моментов. Работой по продвижению книги и чтения в детскую среду должны заниматься специалисты, знающие, как достичь того, чтобы ребенок полюбил чтение. Практика показывает, что родители не всегда обладают необходимыми знаниями и умениями, а непрофессионализм в этой сфере может привести к негативным результатам.

После прозвучавших установочных докладов заместитель генерального директора РНБ по научной работе, президент РБА В.Р. Фирсов открыл обсуждение концепции Программы, подчеркнув значение РБА как общественного органа, объединяющего библиотеки на межведомственной основе и обладающего значительным экспертным потенциалом.

Одной из самых острых проблем в настоящее время является подготовка специалистов в области поддержки книги и чтения. Высшее профессиональное библиотечное образование находится в кризисе: число бюджетных мест сокращается, библиотечные специальности не пользуются популярностью у абитуриентов. Отсутствие моды на чтение в обществе сопровождается отсутствием спроса на профессию библиотекаря. В стране закрыты все кафедры по подготовке детских библиотекарей, а Академия переподготовки работников искусства, культуры и туризма, которая в течение ряда лет готовила промоутеров чтения - специалистов в области продвижения чтения, прекратила свою деятельность. Сегодня отсутствует базовая профессиональная подготовка таких специалистов, нет и системы повышения их квалификации.

В ближайшее время ожидается внедрение нового профессионального стандарта «Педагогбиблиотекарь». В библиотеках работает немало специалистов, не имеющих профессионального библиотечного образования, и возникнет проблема их соответствия этому стандарту по формальному признаку. В целях частичного решения подобных вопросов в РГДБ разработана магистерская программа «Теория и методология библиотечно-информационного обслуживания детей». Обучение рассчитано на практиков, людей, уже выбравших для себя вектор профессионального развития. Подготовка по этой программе уже ведется, она востребована практиками, но не имеет финансовой поддержки.

О.П. Мезенцева подчеркнула важность объединения усилий и взаимного использования ресурсов сферы культуры, образования, книжного дела. Условия финансирования образовательных программ необходимо отразить в будущей Программе. Междисциплинарный подход, воплощенный в ее концепции, должен лечь и в основу создания Программы.

Существующие проблемы в области подготовки и переподготовки кадров, призванных вести деятельность по поддержке чтения, с позиций филологического сообщества подняла профессор Российского государственного педагогического университета им. А.И. Герцена (РГПУ им. А.И. Герцена) М.А. Черняк. Она рассказала о разработанной в РГПУ им. А.И. Герцена магистерской программе повышения квалификации учителей и школьных библиотекарей «Основы смыслового чтения» и подчеркнула важность сотрудничества филологического, педагогического и библиотечного сообществ в этой сфере. Опираясь на текст концепции, М.А. Черняк отметила, что в ней недостаточно учтены возможности и потенциал филологической науки. Ведь часто методики, экспертные оценки, рекомендательные списки строятся на основе данных филологов. Обсуждение концепции Программы со специалистами Института русской литературы (Пушкинского Дома) РАН (ИРЛИ РАН) показало, что нельзя говорить о чтении без опоры на филологическое знание.

Независимая экспертная оценка предложений по разработке концепции Программы была проведена Российской академией образования. Профессора Санкт-Петербургского государственного университета Е.И. Казакова и Т.Г. Галактионова считают, что документ, подготовленный внутри библиотечного сообщества и без учета реалий современного образовательного процесса, 
не вполне согласован с Национальной программой поддержки и развития чтения, действующей до 2020 г., в нем недостаточно учтены новые форматы поддержки чтения. Современное педагогическое сообщество активно работает над включением «текстов новой природы» (комиксы, графические романы, электронные тексты и т. д.) в образовательный процесс, вырабатывает методики работы с ними. Блок «новых текстов» также необходимо учесть при разработке Программы.

Эти идеи в своем выступлении поддержала профессор Санкт-Петербургского государственного института культуры В.А. Бородина. В вузе появился новый образовательный профиль «Коммуникационная деятельность общедоступных и школьных библиотек», благодаря которому удается частично решить вопросы повышения качества подготовки студентов.

Заведующая отделом социологии, психологии и педагогики детского чтения РГДБ Е.А. Колосова обратила внимание на важность дифференцированного подхода к созданию программ, предназначенных для разных возрастных групп. Концепция предусматривает выделение четырех групп: дошкольники, младшие школьники, подростки, юноши. При работе с каждой из них нужны свои методики. Социологические исследования показывают, что $93 \%$ детей имеют домашние библиотеки, однако объем их неизвестен. В то же время только у $15 \%$ россиян есть богатые домашние собрания. Далеко не все взрослые ориентируются в современной детской литературе и могут предложить подросткам книги современных авторов. Из чтения подрастающего поколения ушел целый пласт литературы, который можно отнести к «золотой полке». В регионах почти нет книг новых авторов, а цены на книги не соответствуют возможностям населения. В этих условиях возрастает роль библиотекаря при работе с родителями. Однако за советом к специалистам обращаются менее $10 \%$ родителей, кроме того, они практически не пользуются специализированными электронными ресурсами (например, «БиблиоГид», «ПапмамБук» и др.). Необходимо заниматься популяризацией и продвижением подобных ресурсов среди родителей, поднимать статус библиотекаря как эксперта чтения.

В дискуссии приняли участие представители крупнейших детских библиотек СанктПетербурга и Ленинградской области. Заместитель директора Центральной городской детской библиотеки им. А.С. Пушкина Н.Н. Мазняк подняла тему развития рекомендательной библиографии для детей, в том числе на основе новых информационных технологий. Продвижение лучших новинок современной зарубежной детской литературы может быть более эффективным на основе международного сотрудничества детских библиотек. Она также поставила вопрос о необходимости публикации периодического издания по детскому чтению (например, возобновления журнала «Детская литература») для объединения библиотекарей-практиков, педагогов, семьи с детьми и специалистов по детскому чтению и литературе. Еще одной проблемой для библиотек, решение которой должно найти отражение в Программе, является разработка эффективных технологий комплектования фондов детских библиотек. Существуют серьезные финансовые и таможенные барьеры, тормозящие оперативное поступление книг к читателям.

Заведующая сектором Ленинградской областной детской библиотеки (ЛОДБ) Л.В. Степанова считает, что серьезной методологической ошибкой ведения деятельности по поддержке чтения является объединение профессионального сообщества вокруг «нечтения» детей, в то время как объединяться следует вокруг чтения. Специалистам необходимо быть на стороне ребенка, разговаривать с ним о чтении, рассматривать его в своей деятельности как субъект культуры. Однако сегодня библиотекари имеют мало информации о бытовании книги, не владеют практиками изучения современного детского и подросткового чтения. Такую информацию могут дать антропологические исследования, направленные на преодоление отчуждения чтения от повседневности ребенка, важно понять современную мотивацию детей на чтение. ЛОДБ успешно развивает эту деятельность в партнерстве с коллегами из ИРЛИ РАН, педагогами вузов, музеями.

С этим согласилась заведующая Исследовательским центром «Библиотека. Чтение. Молодежь» Российской государственной библиотеки для молодежи М.М. Самохина, отметившая, что большинство усилий библиотек связано с привлечением к чтению нечитающих и малочитающих детей, в то время как надо обязательно работать с продвинутыми группами, с активно читающими детьми.

Один из разработчиков концепции Программы, главный научный сотрудник РГДБ В.П. Чудинова, включившись в дискуссию, остановилась на том, что принцип «ребенок как субъект деятельности» был заложен в текст на начальном этапе его разработки, но в итоговом варианте документа не получил должного развития.

Позиция представителей школьных библиотек нашла отражение в докладе президента Ассоциации школьных библиотекарей русского мира Т.Д. Жуковой, указавшей на такую проблему, как «бытовой» уровень подхода к чтению в органах исполнительной и законодательной власти. Она охарактеризовала модернизацию образования на современном этапе как необходимость изменения качества мышления. На сегодняшний день согласно утвержденной Министерством образования и науки РФ «Концепции развития школьных информационно-библиотечных центров» библиотека рассматривается как «место коллективно- 
го мышления и творчества, ключевой элемент инфраструктуры чтения, центр грамотности по формированию читательских навыков» [4], как место, «где у ребенка все получается». Однако для реализации современных задач нужны резонансные проекты, которые по-новому будут открывать обществу профессию школьного библиотекаря. В качестве такого проекта Т.Д. Жукова представила участникам круглого стола проект «Материнское чтение», предложила привлечь специалистов по когнитивистике к обсуждению концепции и созданию Программы.

Мнение писательского сообщества представил детский писатель Н.Н. Прокудин. Опираясь на свой многолетний опыт проведения различных мероприятий, в частности литературных марафонов и литературных десантов в провинциальных городах и селах, он отметил, что современные дети не знают ныне живущих писателей, лишены литературных новинок. $K$ сожалению, многие школьные библиотеки комплектуются преимущественно учебниками, а их помещения зачастую используются для проведения учебных занятий. В результате ограничиваются возможности библиотек по работе с книгой. Особое внимание Н.Н. Прокудин уделил организации совместной деятельности писателей, школьных и детских библиотек. Писателям бывает трудно попасть в школу на встречу с детьми, так как для этого требуется ряд согласований и разрешений. Но только совместная работа, знакомство и общение детей с писателями и их книгами на базе библиотек позволяет пробудить у ребенка любовь к книге и чтению.

Мысль о существующей в обществе недооценке роли чтения в формировании подрастающего поколения, личности будущего гражданина страны, в том числе и основными участниками процесса приобщения детей к чтению - педагогами, родителями, библиотекарями, звучала во многих выступлениях. Как показывает практика, важность создания и принятия Программы на государственном уровне необходимо доказывать и обосновывать вновь и вновь в разных социальных и профессиональных сообществах и властных структурах.

Разработчики концепции Программы провели ряд научно-практических конференций, круглых столов и дискуссий. Важно расширять круг общения, выходить за привычные профессиональные границы. Дискуссия ярко продемонстрировала, что приобщение детей к чтению до сих пор не осознается как важная государственная задача даже специалистами гуманитарного профиля, родителями и чиновниками. Требуется еще много усилий, чтобы доказать актуальность этой задачи в современном мире «всеобей грамотности».

Участники Международной научно-практической конференции «Чтение: многообразие возможностей» поддержали проделанную работу и высказались за скорейшее принятие решения о разработке Национальной программы поддержки детского и юношеского чтения в Российской Федерации на государственном уровне. Они согласились с тем, что деятельность по продвижению чтения «необходимо начать рассматривать как приоритетное направление в культурной и образовательной политике государства, имеющее важное значение для будущего страны» [5, с. 3].

Поддержка детского и юношеского чтения была выделена как важное самостоятельное направление программы действий в резолюции пленарного заседания секции «Литература и чтение» на V Санкт-Петербургском международном культурном форуме. Резолюция, включившая в себя предложения по стратегическим целям и инициативам развития книжной культуры и чтения в России, была направлена в органы законодательной и исполнительной власти.

\section{Список источников}

1. О форуме [Электронный ресурс] // СанктПетербургский международный культурный форум : сайт. URL: https://culturalforum.ru/ru/about (дата обращения: 01.02.2017).

2. Виртуальная конференция «Чтение: многообразие возможностей» [Электронный ресурс] // Чтение-21 : сайт.URL: http://chtenie-21.ru/virconf (дата обращения: 01.02.2017).

3. Международная научно-практическая конференция "Чтение: многообразие возможностей», 2-3 декабря 2016 г. : [видеозапись] [Электронный ресурс] // Центр чтения Российской национальной библиотеки : сайт. URL: http://www.nlr.ru/prof/ reader/component/content/article?id=20452 (дата обращения: 01.02.2017).

4. Приказ Министерства образования и науки РФ от 15 июня 2016 г. № 715 «Об утверждении Концепции развития школьных информационно-библиотечных центров» [Электронный ресурс] // Гарант.ру : информационно-правовой портал. URL: http://www. garant.ru/products/ipo/prime/doc/71338750/ (дата обращения: 01.02.2017).

5. Концепция Национальной программы поддержки детского и юношеского чтения в Российской Федерации / Федеральное агентство по печати и массовым коммуникациям. Москва, 2016. 25 с. 


\title{
About Supporting Children and Youth Reading at the 5th Saint Petersburg International Cultural Forum
}

\author{
Lyudmyla V. Glukhova, \\ The National Library of Russia, 18 Sadovaya Str., St. Petersburg, 191069, Russia \\ E-mail: consult@nlr.ru \\ Vera V. Yalysheva, \\ The National Library of Russia, 18 Sadovaya Str., St. Petersburg, 191069, Russia \\ E-mail: consult@nlr.ru
}

\begin{abstract}
The article introduces the work of the Round table "Who and why need a program supporting children and youth reading?", held on 3 December, 2016 at the National Library of Russia in the framework of the International Scientific-Practical Conference "Reading: Diversity of Opportunities" at the 5th St. Petersburg International Cultural Forum. The event participants discussed the Concept of establishing the National program for support of children and youth reading in the Russian Federation. Experts in the field of culture and education expressed their suggestions for inclusion in the National program for support of children and youth reading. It was stated the need for the development and adoption of such a document at the government level.
\end{abstract}

Key words: National Program for Support of Children and Youth Reading in the Russian Federation, Reading Promotion, Support for Children and Youth Reading, Professional Event, the 5th St. Petersburg International Cultural Forum.

Citation: Glukhova L.V., Yalysheva V.V., About Supporting Children and Youth Reading at the 5th Saint Petersburg International Cultural Forum, Bibliotekovedenie [Library and Information Science], 2017, vol. 66, no. 1, pp. 49-54.

\section{References}

1. O forume [About the Forum], Sankt-Peterburgskii mezhdunarodnyi kul'turnyi forum [The St. Petersburg International Cultural Forum]. Available at: https://culturalforum.ru/ru/about (accessed 01.02.2017).

2. Virtual'naya konferentsiya "Chtenie: mnogoobrazie vozmozhnostei" [The Virtual Conference "Reading: a Variety of Opportunities"], Chtenie-21 [Reading-21]. Available at: http://chtenie-21.ru/virconf (accessed 01.02.2017).

3. Mezhdunarodnaya nauchno-prakticheskaya konferentsiya "Chtenie: mnogoobrazie vozmozhnostei", 2-3 dekabrya $2016 \mathrm{~g}$. [The International Scientific and Practical Conference "Reading: Diversity of Opportunities", 2-3 December 2016], Tsentr chteniya Rossiiskoi natsional'noi biblioteki : sait [The Center of Reading of the National Library of Russia: the Website]. Available at: http://www.nlr.ru/prof/ reader/component/content/article $? \mathrm{id}=20452$ (accessed 01.02.2017).

4. Prikaz Ministerstva obrazovaniya i nauki RF ot 15 iyunya 2016 g. № 715 “Ob utverzhdenii Kontseptsii razvitiya shkol'nykh informatsionno-bibliotechnykh tsentrov" [The Order of the Ministry of Education and Science of the Russian Federation of 15 June 2016 no. 715 "On Approval of the Development Conception for School Library and Information Centers"], Garant. ru: informatsionno-pravovoi portal [Garant.ru: the Information and Law Portal]. Available at: http:// www.garant.ru/products/ipo/prime/doc/71338750/ (accessed 01.02.2017).

5. Kontseptsiya Natsional'noi programmy podderzhki detskogo i yunosheskogo chteniya $v$ Rossiiskoi Federatsii [The Conception of the National Program for Children and Youth Reading Support in the Russian Federation]. Moscow, 2016, 25 p. 